\title{
Color in Architecture is it Just an Aesthetic Value or a True Human Need?
}

\author{
Ahmed Hosney Radwan \\ Department of Architecture \\ College of Fine Arts, Helwan University \\ Cairo, Egypt
}

\begin{abstract}
Color is considered as an integral element of our environment, not only represented in the living organisms of the natural environment but also in the man-made various environments, Color always played an important role in the human evolutionary processes from the simple human shelters to the huge mega cities The environment and its colors are perceived, and the brain processes and judges what it perceives on an objective and subjective basis. Psychological influence, communication, information, and effects on the psyche are aspects of our perceptual judgment processes. Hence, the goals of color design in an architectural space are not relegated to decoration alone (Mahnke, 2015). This paper aims to study the color as a human nature that has been related to the built-in Environment, and how color as a human activity, is important to the level of being a need, not only to achieve some decorative or aesthetical values, but also to fulfill some needs of the human being that they cannot live without, starting from studying color in natural environment till color as an important component of Man-made environment represented in architectural and urban contexts, this paper also questions the importance of color in humans life, and how it is related and important to many vital activities of the human being, not only as a fashion or an architects Design for a specific building or an urban planner setup.
\end{abstract}

Keywords-Color, Color in natural environment, Color in Architecture, Color wheel, Color psychology, Neuropsychological Aspects, Ergonomics and Color.

\section{INTRODUCTION}

Colors are a standout amongst the most essential things encompassing us from style perspective, they can change point of view, control measurements, even inspire emotions if utilized right. In the same way the colors are impacting our intuitive and activities, responses, they could raise your pulse or even smother your ravenousness. Specialists are utilizing colors as a part of different routes on ordinary premise to control the view of a thing or business brand. For instance, in traffic: Red is stop and green is go, depending on your discernment and experience, each color can control your recognition, and such regular experiences as the red and green lights are the ones that will manage us to a typical comprehension and observation around the world.

\section{A. Definition of color}

According to Wikipedia color is characterized as "the visual perceptual property comparing in people to the categories called blue, red, green, yellow and others. Color gets from the range of light (dispersion of light power vs wavelength) collaborating in the eye with the phantom sensitivities of the receptors of the light. Color classes and physical determinations of color are additionally connected with articles, materials, light sources, and so on., taking into account their physical properties, for example, light retention, reflection, or emanation spectra. By characterizing color, colors can be recognized numerically by their directions.

Since view of color stems from the fluctuating spectral sensitivity of distinctive sorts of cone cells in the retina to diverse parts of the range, colors may be characterized and measured by the extent to which they fortify these cells. These physiological or physical measurements of color, then again, don't completely clarify the psychophysical view of shading appearance.

The art of color is now and again called chromatics, chromatography, colorimetry, or essentially color science. It incorporates the view of color by the human eye and cerebrum, the beginning of color in materials, color hypothesis in art, and the material science of electromagnetic radiation in the obvious extent (that is, the thing that we regularly allude to just as light)."

\section{B. Perception of color}

In the most recent eleven decades, exact perceptions and experimental studies have demonstrated that humanenvironment-response in the architectural environment is to an expansive rate in view of the tactile impression of color. These studies incorporate the controls of psychology of architecture, psychology of color, psychology of neuro, visual ergonomics, psychosomatics, and so on. To put it short, it affirms that human reaction to color is all out - it impacts us mentally and physiologically

The American Faber Birren, considered the father of psychology of practiced color (originator of the OSHA hues) and the first to build up the job of color specialist in 1936, announced: "The investigation of color is basically a psychological \& mental science, for the term color itself alludes to sensation."

Color is a tangible recognition, and as any tactile discernment, it has impacts that are typical, affiliated, synesthetic, and enthusiastic. This plainly obvious rationale has been demonstrated by experimental examination. Since the body and brain are one element, neuropsychological angles, psychosomatic impacts, visual ergonomics, and color's mental impacts are the segments of color ergonomics. These being considerations of design goals that request adherence to secure human mental and physiological prosperity inside of their manmade environment. The color designer/ specifier has the undertaking of knowing how the gathering of visual incitement, its handling and evoked reactions in conjunction with the hormonal framework, delivers the best potential outcomes for the welfare of people. This is of most extreme significance in 
shifted situations, for example, medicinal and psychiatric offices, workplaces, modern and creation plants, instructive offices, homes for the elderly, remedial offices, and so on. Each inside of themselves having distinctive undertaking and work regions.

\section{COLOR AS A HUMAN NEED}

Why is color available with us people in this world? This inquiry, cited from the Swedish physicist Pehr Sällström, could serve as a beginning stage for an investigation of the rich and stimulating occurrence of color. Color could be understood by numerous branches of science, additionally amongst artists, for example, Paul Klee and Frida Kahlo and writers, for example, Björner Torsson. In any case, neither light nor color can be completely depicted; however much we attempt there are dependably measurements that compass past language and investigation. Light and color are tangible qualities that must be experienced (Anter, 2008).

\section{A. Color as mentioned in the Holy Quraan}

The utilization of colors in the Quran are of two sorts; either color is unequivocally said as (black, white, green and red) or certainly allude to the color and could be induced through verses while recalling words (the light and the flame, day and night, darken). The colors in the holy Quran convey typical and symbolic meanings, tasteful or moral destinations and the utilization of colors in the Quran have basic intentions. Most known colors are said in verses (Ayat), as the colors have multifaceted parts in both moral and sensual purposes. They have numerous results that influence the audience's psychological gathering (Al-Shawi, 2014).

"Greenness" is said several times in the verses of the Quran; portraying the condition of the occupants of heaven, and what encompasses them of favors in an extravagance environment of bliss, delight and consolation.

For example:

- Allah says in the holy Quran: (Reclining on green Cushions and rich Carpets of beauty) (SURAH AL RAHMAN: 76).

- Allah says in the holy Quran: ( Upon them will be green Garments of fine silk and heavy brocade, and they will be adorned with bracelets of silver; and their Lord will give to them to drink of a Wine Pure and Holy) (SURAH AL INSAN:21)

- Allah says in the holy Quran: (They will recline on Carpets, whose inner linings will be of rich brocade: the Fruit of the Gardens will be near (and easy of reach)) (SURAH AL RAHMAN: 54).

Ardtcham expressed that colors apply a stamped impact on people. With a specific end goal to demonstrate this thought various examinations have been led, exhibiting how colors influence our eagerness and carefulness, it likewise gives a chilly or warm feeling, brings bliss and bitterness and affect our identity and the way we see life. These days, hospitals weigh up the part colors play in changing the internal of individuals, by considering the experts proposals about the colors that ought to be utilized inside healing centers for the walls and garments.
Trials have shown the incitement of the nervous system by the yellow color. The orange color brings consolation and quiet, the blue color makes individuals feel chilly not at all like the red which makes them feel warm. In any case, it was found that the color of euphoria and joy is the green color, which makes it the most loved color for surgical rooms and specialist's uniform.

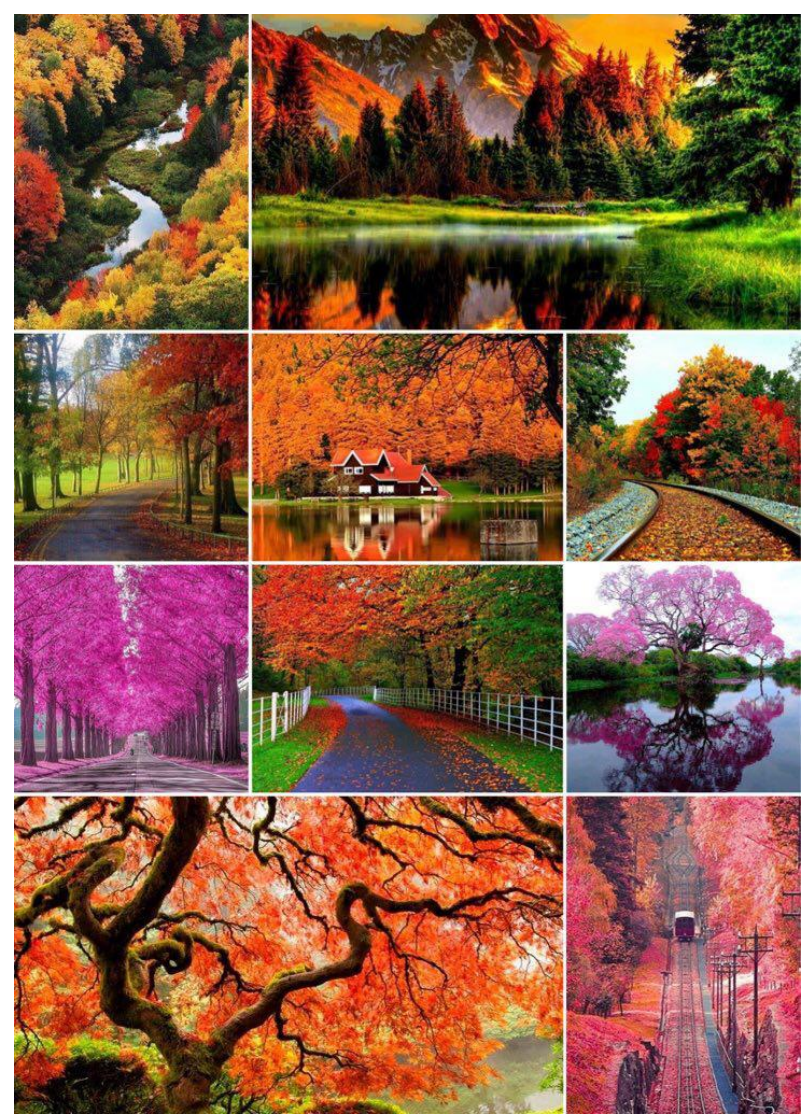

Figure 1: Nature is mainly characterized by Colors.

One sample concerning this gigantic impacts colors have, goes to our brains, concerning the examination that was conveyed in a London bridge called "black friar" known as the suicide bridge, the same number of the suicides were conferred from it. At the point when its color was changed from dark to a decent green color the rate of suicide has declined vastly. It is realized that the green color facilitates the vision because of its little vision region next to its medium wave length which is shorter than the red one and more that the blue one (Diab, 2015).

The colors in the Quran convey typical essences, tasteful zones and moral issues. The utilization of colors' implications in the Quran is of incredible significance. There are the most known colors said in the verses and assume urgent part as they have tactile and moral capacity which their undertones affect the human soul. That the utilization of colors in the Quran reacted to two sorts, once in a while the color is specified unequivocal, for example, black, white, green and red and some of the time it doesn't say the word specifically, yet rather surmised the presence of color through the while utilizing words (al-subih (the sunlight), night, darkness, light of heaven and fire) (Al-Shawi, 2014). 


\section{WIDER UNDERSTANDING OF COLOR}

Color is an expressive component in architectural design and can be utilized to highlight the building character and make unity and harmony, or it can be intentionally differentiating to charge or highlight. It might influence the route in which individuals react to their surroundings and can upgrade a state of mind of quiet or euphoria (Bell, 2008).

Colors are a component of both the man-made and natural environments. They pass on messages of assorted types and perform a wide assortment of capacities, educating, sorting out, and notice. In any case, they additionally fill an aesthetic need, influencing the announcement, impact, and acknowledgment of articles and spaces. While individuals' responses to color shift broadly, in design questions it is still conceivable to set up for the most part legitimate color ideas to coordinate the desires of the different gatherings of clients. (Gerhard Meerwein,Bettina Rodeck Klampenborg, Frank H. Mahnke , 2007).

Color is a component of our visual observation that is identified with how our eyes see light. We separate these observations and name them yellow, red, blue, and so on. Designers use color in the decision of materials used to develop a building. These color decisions can be entirely unobtrusive, for example, utilizing a warm, yellow conditioned cement rather than a frosty dark base, or utilizing a brownish block rather than the conventional red. Then again, the designer must consider the color impact of each component of a building's development, from the earthy colors of essential development materials like marble, wood, stone and block, to the broad assortment of colors accessible for paint, entryways, windows, siding, and trim. Once picked, the architectural drawings and test sheets tell a contractor precisely what color building materials to utilize while developing a structure (Aesthetics, 2015).

\section{A. Color Psychology}

In spite of offering character to space, color is likewise valuable in affecting human behavior, choice making, health and substantially more with or without our acknowledgment. As such, color is an unpretentious incitement with striking effect has been very influencing human lives physically, mentally, physiologically and sociologically on daily basis, and has now been generally acknowledged. Each individual see color distinctively depending how one's apparent the phenomenon. As indicated by Fehrman and Fehrman (2004), color is individuals' dream where the world is accepted to be colorless. They clarified that light is a vital component to color appearance. Color is seen by the human eyes just when there is a light on the substance. It is a vitality vibration of inconceivable electromagnetic band that create wavelengths of electromagnetic range, for example, gamma beams, X-beams, radio frequencies, obvious light, infrared beams and bright beams. Color is just a little piece of an unlimited electromagnetic range that can be seen by human eyes from around 400-nanometers to 700-nanometer approximation. Noticeable light is measured in nanometer and a nanometer is equivalent to 1 millionth of a millimeter. Interestingly, the vitality of color wave can likewise be detected through skin (Fehrman and Fehrman, 2004; Jin et al., 2005) most likely utilized by individuals with visual debilitation to perceive color. In like manner understanding, color is partitioned into cool and warm color, where it is separating by normal for its wavelengths. Blue, green and purple are viewed as cool color range that has shorter wavelength contrasted with red, orange and yellow. Red, orange and yellow are ordered as warm colors with red as the longest wavelength saw by our eyes. Moreover, every length has diverse impacts to human with or without our worry (Jalil, 2011).

A standout amongst the most striking results concerning color intentions and color mood affiliations is its consistency diversely starting with one individual then onto the next and from group to another. The colossal number of studies looking at human subjects around the world, for example, men to ladies, kids to grown-ups, laymen to designers, and even monkeys to people demonstrate that color is a universal visual language comprehended by all.

Color impression and the message it passes on is of most extreme significance in making the mental mood or vibe that backings the capacity of a space. A classroom has an alternate capacity than a hospital room; an office space is not a generation line, and so on.

Examples concerning colors and what they express:

- Pastel yellow gives the impression of sunny, neighborly, and delicacy. The message in the inside space is invigorating, shine, comfort.

- Red is exciting, enthusiastic, provocative, blazing, and forceful. The message in the inside is forceful, propelling, overwhelming.

- Green is adjusting, regular, quiet with the message of effortlessness, security, parity.

- White communicates open, limitless, unbiased, and sterile. The message being virtue, sterile, vacancy, hesitation.

Clearly this is a little illustration since all colors change their character when altered in their delicacy element (light to dull) and immersion.

\section{B. Neuropsychological Aspects}

A part of neuropsychological examination is to find how the brain forms and responds to tangible data originating from the outside world and how this influences people. Particularly imperative for the color specifier is the examination concerning the presentation of two perceptual extremes in the environment known as sensory deficiency and sensory over-burden, additionally termed dreariness (or under incitement) and overstimulation. Included is the reticular development which dependably looks to keep up a level of commonality, yet it can (and will) breakdown. Stress research has demonstrated that conditions of physical monotony or overstimulation can trigger brokenness in the life form. Dullness sends powerless natural signs and overstimulation confounding signs. Ponders have demonstrated that individuals subjected to an under animated environment hint at anxiety, peevishness, over the top passionate reaction, challenges in focus, discernment issue, and at times, an assortment of more amazing responses. The essential indications of an under fortified environment are feeble colors' intensities, monochromatic harmonies, colorless colors, frail or dreary color differentiations. Overstimulation results in changes in the rate of breathing, increment of heartbeat rate and blood pressure; increment in muscle pressure; psychiatric responses of changeable types; and presumably intensified medical outcomes, for example, expanded vulnerability to contamination, coronary ailment and ulcers. Stress research has 
demonstrated these indications as common impacts on persons who have been subjected to overstimulation. The essential indications of an overstimulated environment are solid color intensity (saturated highly), color harmonies that are excessively unpredictable or indistinguishable, contrasts that present themselves excessively solid, an excess of complex visual color examples.

In a research paper by Dr. R. Küller (Architectural Psychology Department at the University of Lund), entitled An Emotional Model of Human-Environment Interaction, it states: "New research in the field of neuropsychology demonstrates that full of feeling reactions are speedier and more fundamental than intellectual procedures."

\section{Architectural Environments - Emotions and Psychosomatics}

Sune Lindstrom (professor in architecture) commented in 1987: "With each specific building item, it is the unconstrained passionate response that is of significance to us." the earth produces feelings which thusly is connected to psychosomatics. Psychosomatic pharmaceutical underlines that physical issue might start through mental variables, be disturbed by them and the other way around. It is basic information that stress might bring cause headaches, nervousness makes the heart beat quicker, and irritation and misery might influence the stomach, to name the most well-known happenings. Obviously the list incorporates hypertension, heart palpitations, headache pains, dermatitis, weakness, and so on.

Exploratory examination has also settled the connection to PNI - Psycho-Neuro-Immunology which plainly demonstrates that systems of nerve fibers and sub-atomic extensions unite the mind and the body with one another and that feelings enter totally into the cells of the life form. From this time forward, exploration shows that a positive passionate mood reinforces the body's digestive system against infection, while a negative enthusiastic mood has a debilitating impact.

In respect to architects is the answer given by David Felten (Professor for Neurobiology and Anatomy for the School of Medicine at the University of Rochester, New York) to the inquiry: "When does the communication between the psyche and the body associate?" Felten replied: "The minute we start to see tangible incitement "

\section{Visual Ergonomics and Color}

Most likely one of the slightest known elements of fitting color detail is its part in protecting visual proficiency and comfort. The eye's adjustment process includes the prompt response of the eye to changes in the level of enlightenment. Bringing down light reflectance causes the pupil to widen, and vice versa for higher reflectance. The eye sees luminous density and not the illuminance intensity. Luminous density is the thing that the eyes get when light is reflected from a surface (walls, floors, furniture). In case of that the contrasts between the luminous densities in the perspective are excessively extraordinary, the iris muscle is strained because of consistent alternation, in this way creating eye weakness. Researches have demonstrated that suitable contrasts in luminous density can lessen eye weakness and raise visual sharpness, causing additional efficiency. The colors of surfaces retain and mirror some of the light. These estimations are alluded to as light reflection values. Basically all paint organizations demonstrate to them on their color fan decks under LR or LRV. The universal standards are the 3-1 light reflection ratio inside of a space. This recommends that floors ought to reflect around $20 \%$, walls $40-60 \%$, furniture $25-40 \%$. The 3-1 assignment implies the lightest color $(60 \%)$ partitioned by the darkest $(20 \%)$ is a proportion of $3-1$. On the other hand, visual ergonomists are not designers of color. A yellow wall at $60 \%$ is not a yellow any longer but rather a tan. The main arrangement is if the walls are raised to $75 \%$ light reflection for instance, so should then be the rate of floor and furniture additionally be raised to protect that there still exists control of compelling differentiations in light and dark. Fascinating fact is that if these guidelines were known by the community of designers, there wouldn't be white walls - only roofs are where $80-90 \%$ is approved.

\section{E. The Application Gap}

Dr. R. Küller composed in his research (D15:81 on the impacts of light and color for the Swedish Council for Building Research) that: "Throughout this work, it has gotten to be clear there is a gigantic measure of actualities and results that is never considered by and by and training. Consequently, one finds a crevice between researches on one hand and rehearsals on the other". "The Infamous Application Gap".

Dr. R. Küller's announcement echoes the worries of the IACCInternational Association of Color Consultants/Designers that was established in 1957 with the cooperation of roughly 50 artists, architects, psychologists, teachers, and researchers from 12 nations. The inspiring force being a nonattendance of capable training in the professions that request the utilization of color. With the coordinated effort of perceived national and global experts, an interdisciplinary training/accreditation project was set up in Salzburg, Austria under the direction of Dr. Heinrich Frieling, author of the Institute of Color Psychology of Germany. It is currently known as the IACC Academy for Color and Environment. Until today, this project is led likewise in the United States for all universal English talking members; Italy, Milan, and the IACC Schools of Japan for Color and Interior Design, Fukuoka, Nagoya, Kyoto, Tokyo, Hiroshima, and Sapporo. Undoubtly, the supposition that color is close to decoration and color details can be fulfilled or settled by individual explanations or the accompanying of color patterns and plan phrases in current manner is completely false and counterproductive. Others conscious configuration puts the individual in the focal point of its worry and reason. Along these lines, it ought to show enthusiasm for human welfare and nobility. 


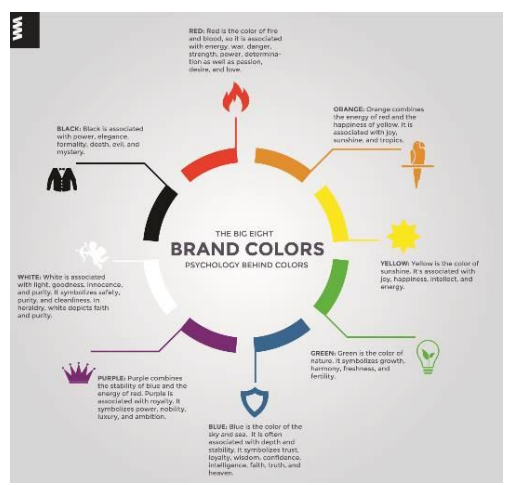

Figure 2: Color Wheel
IV. COLOR WHEEL

\section{COLOR \& HUMAN BODY}

\section{A. Color and Energy}

Numerous researchers, particularly quantum physicists, are tolerating the way that everything in the Earth radiate vitality. They know this in light of the fact that the vitality can be distinguished utilizing progressed bioelectric advancements. One of these advancements is called Kirlian photography; which means an electrographic recording method which works by putting an article on top of a sheet film, which is put on top of a metal plate and afterward it is highly voltage charged. This procedure causes a crown release between the item and the metal plate, which is recorded as light examples of hues by the film. Kirlian photography can likewise be utilized to identify energies radiated from the human body.

\section{B. What is the human aura?}

If you study energy mechanics profoundly enough, you ought to realize that everything is made out of energy and that it is a projection of energy. Since everything is made of energy, then everything radiates energy in some way or another. The human body radiates a wide range of types of energy. One of them is known as the human appearance, which is a bioenergy field that is made of a wide range of layers and hues. Its shape appears to be like an egg that encompasses the whole body. Numerous energy healers trust that the emanation contains data identified with the physical, enthusiastic, mental and profound body. They additionally trust that the data in the human atmosphere can tell the health condition of the human body.

\section{Aura colors and meanings}

The human aura is accepted to be made of 15 distinct layers of colors of energy that are all unified. Most studies of the human aura are frequently focusing around the initial 7 layers of the human aura. This article will go further by investigating the initial 12 layers of the emanation and their hues and implications. The principal layer of the human aura is the on nearest to the body.

Layer 1: represents the color red and the etheric body.

Layer 2: is connected to the passionate and essential body. It is orange in color.

Layer 3: is associated with the mental body and is yellow in color.
Layer 4: represents to the astral body and discharges a green color.

Layer 5: is connected to the model body and is blue in color. Layer 6: represents the saintly body and is indigo in color.

Layer 7: is associated with the keriatric body and radiates a violet color.

Layer 8: is connected to the monadic body and has a gold color. Layer 9: is silver in color and represents the keriatric body.

Layer 10 is joined with the christiac body. It represents the colors blue-black.

Layer 11: is connected to the buddhaic body and is silver-black in colors.

Layer 12: represents the nirvanic body and transmits white colors.

\section{Healing using Colors.}

Numerous energy healers trust that when the colors of the human aura are contaminated and out of equalization, they can bring out negative consequences for the body, prompting wellbeing issues. Here is a list of aura colors and their implications:

- Deep red: Grounded, strong will power, survival oriented

- Dark red: Grounded, solid self-discipline, survival situated

- Dim red: Anger

- Clear red: Active, competitive, sexual, and enthusiastic

- Orange: Energy, force, inventive, strengths, fearless

- Orange-yellow: Scientific, thorough, obsessive

- Yellow: Creative, lively, character, mindfulness, power, learning, interest

- Yellow-green: Loving, outgoing

- Green: Environment, development, equalization, love and nature

- Dim green: Jealousy, low self-regard, anger

- Blue: Cool, quiet, touchy, manifestation

- Dull blue: Fear of self-expression

- Indigo: Spontaneous, unrealistic, clear minded

- Violet: Idealistic, divine astuteness, improvement

- Silver: Abundance, sustaining.

- Brilliant pink: Sensitive, aesthetic, love, empathy, perfection.

- Dull pink: Undeveloped, untrustworthy.

- Gold: Enlightenment, astuteness, instinctive mastermind

- White: Pureness, harmony, superior 


\section{COLOR IN NATURAL ENVIRONMENT}

Observing the natural habitat, color is a unique trademark in it, from colors of blossoms, to butterflies, to woods, these living creatures propelled individuals, and that could clarify why people were identified with their tendency

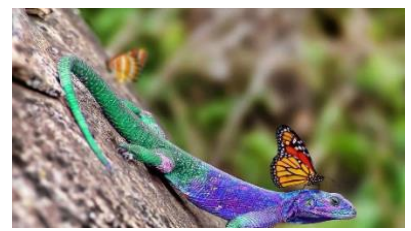

Figure 3: Colorful Lizard, Example of Colors in Animals.

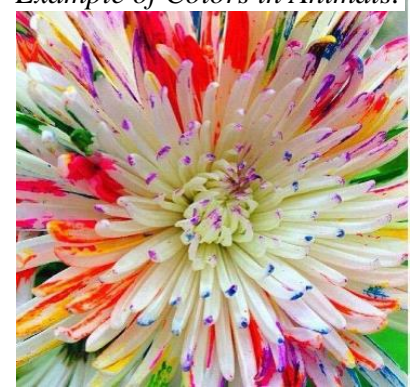

Figure 4: Colorful FlowerExample of colors in plants
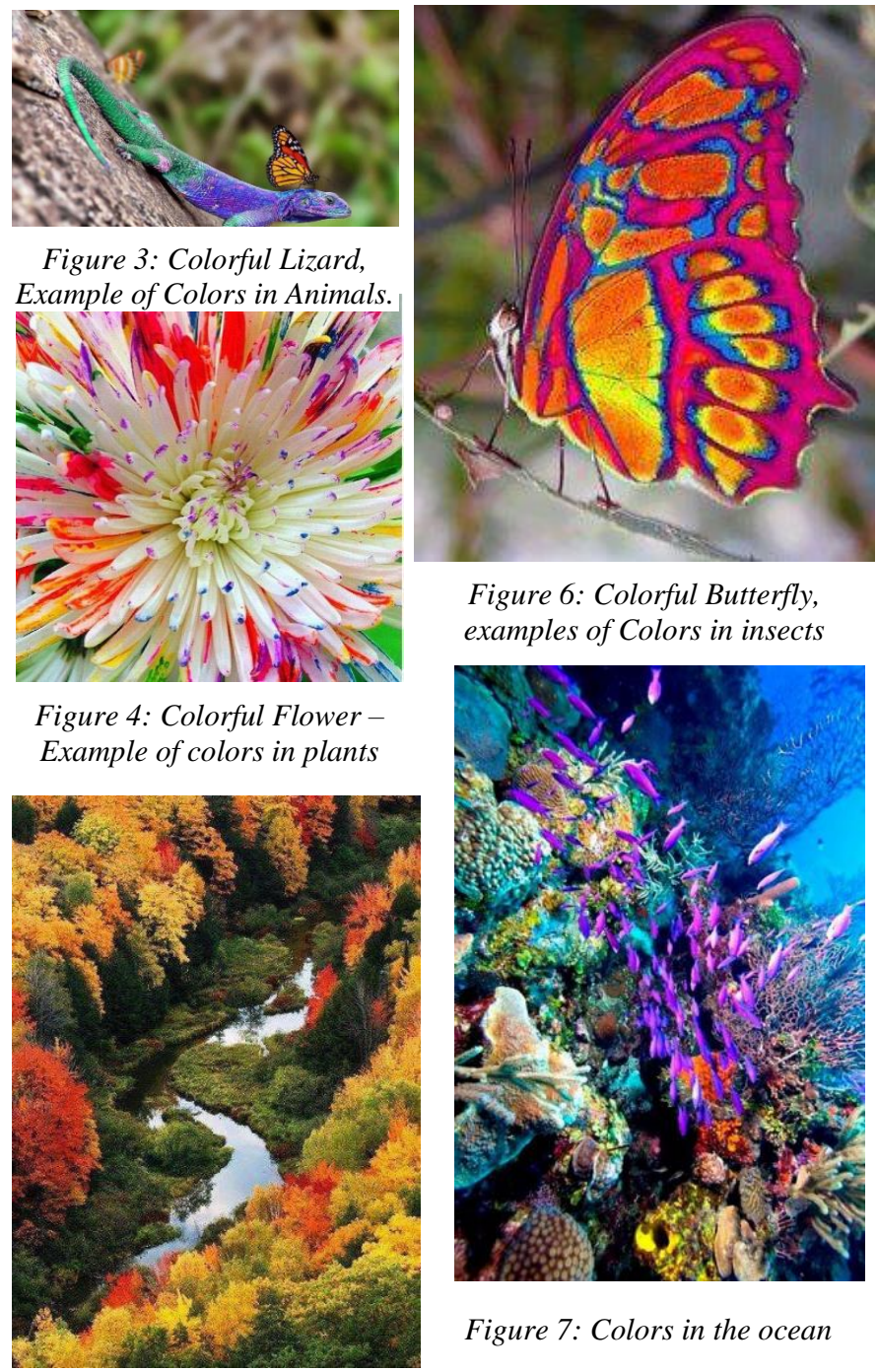

Figure 6: Colorful Butterfly, examples of Colors in insects

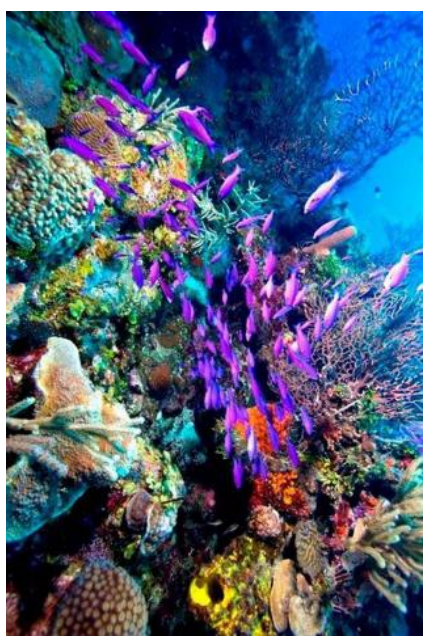

Figure 7: Colors in the ocean

Figure 5: Nature containing diversified colors.

\section{COLOR IN MAN-MADE ENVIRONMENT (ARCHITECTURE DESIGN).}

\section{A. Color in Ancient Egyptian Architecture}

Egyptian Color Palette (From c.3,000 BCE):

Artistic work painting in Ancient Egypt was utilized to beautify tombs, sanctuaries, open structures, and clay ceramics. Painting not just colored the walls of New Kingdom tombs, but also the houses and castles of the living with extraordinary excellence. Magnificent scene frescos including reeds, water, feathered creatures, and creatures upgraded the walls, roofs, and floors of the royal residences. Unfortunately, after the nineteenth Dynasty (1295-1186 BCE), under Pharaohs like Ramesses I, Seti I, Merenptah, Amenmesse and others, there was a relentless downturn in the nature of such work of art. There were different

types of painting rehearsed, yet on a littler scale, for example, painting on papyrus, furniture, and wooden caskets, which persevered until the most recent times of Egyptian history.

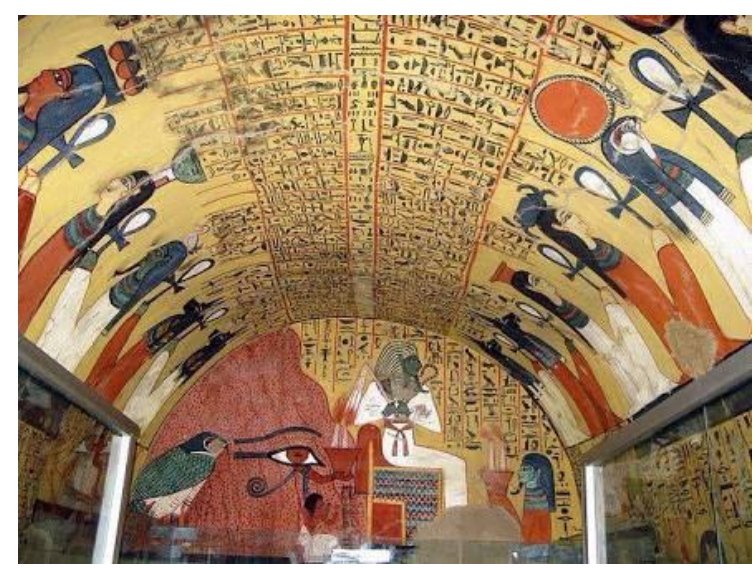

Figure 8: The use of colors inside ancient Egyptian tombs describing their lives in details.

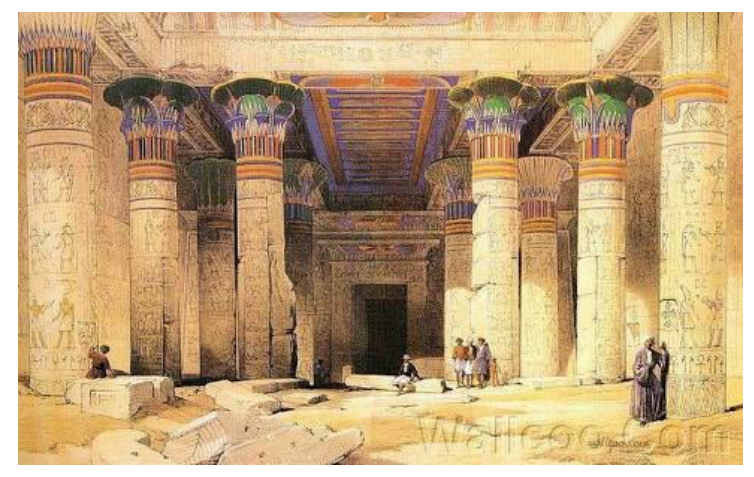

Figure 9: The use of colors in temples, imitations of nature.

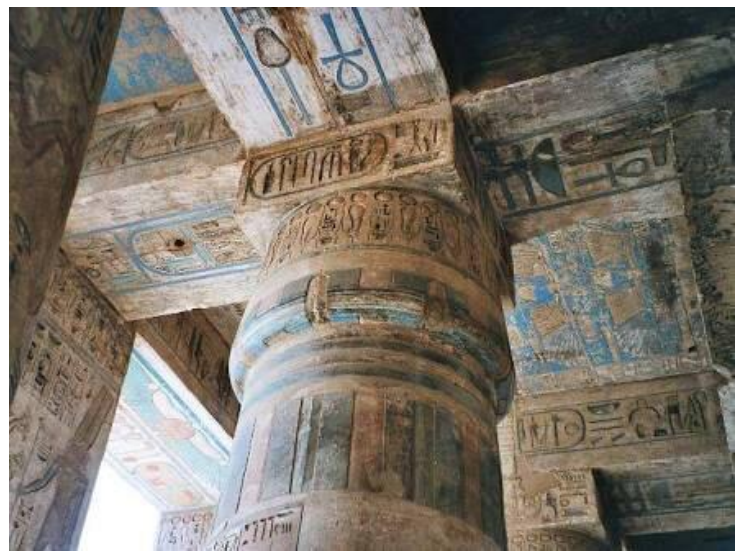

Figure 10: The use of natural colors on columns of ancient Egyptian temples, prolonged for centuries. 


\section{A.1 Colors Used by Egyptian Painters}

Like all parts of art in Ancient Egypt, the utilization of colors in Egyptian depictions was profoundly typical and entirely managed. Egyptian painters depended on six colors in their palette: red, green, blue, yellow, white and dark.

Colors

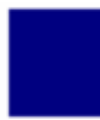

Blue

Sky, Water, the Heavens, Primeval Flood, Creation and Rebirth

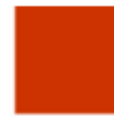

Red

Life, Fire, Victory, Anger, Hostility and

Chaos

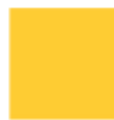

Yellow Imperishable, Etemal and Indestructible.

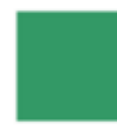

Green Fertility, Vegetation, New life, Joy, Growth and Regeneration

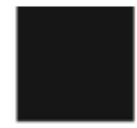

Black

Death, Night, Endurance, Stability

White

Purity, Power, Cleanliness and Simplicity

Figure 11: Color Meaning Chart

\section{B. Architects and perception of colors}

Le Corbusier (1887-1965) is thought to be a standout amongst of the architects of the twentieth century. Right up 'til the present time, Le Corbusier's work has affected architectural planning and design. For Le Corbusier, colors was pretty much as critical as format or frame for his buildings and designs.

Stimulated by the adjusted colors in nature, Le Corbusier made his Polychrome Architectural with a view of both sharp and aesthetic determination of colors.

The remarkable Swiss artist built up this one of a kind arrangement of colors in two stages. The primary assortment was published in 1931, the second one was in1959.

In 1931, it involved 43 passive colors and in 195920 intense colors. The assortments of colors depend on rehashing a couple of chosen fundamental colors which Le Corbusier used to determine extra colors. They are reliably naturally harmonic, may be consolidated in an amazing way and, right up 'til the present time, have been the noteworthy aftereffect of his experience as an architect, artist, designer, and colors designer.

"Every one of us, as per our taste and responses, support one or more of the commanding plans of colors. Every person is drawn towards some specific harmony which appears to unite with his inward thoughts. The commonsense trouble is to show colors in a manner that the individual can recognize his own particular sympathy." and that is the reason behind inventing colored keyboards. (Le Corbusier. salubra).
Stimulated by the delightful colors theme in architecture, I got myself confronted with an Austrian artist (and also engineer, however without formal preparing) called Friedensreich Hundertwasser who chose to announce war on straight lines. His designs helped me to remember the Catalan modeler Antoni Gaudí in its biomorphic manifestations. Yet, it was not the utilization of unpredictable shapes in the buildings he composed what got my consideration, however the utilization of a limitless cluster of splendid hues, both in exteriors and inside of structures. He considered the colors a fundamental piece of architectural design.
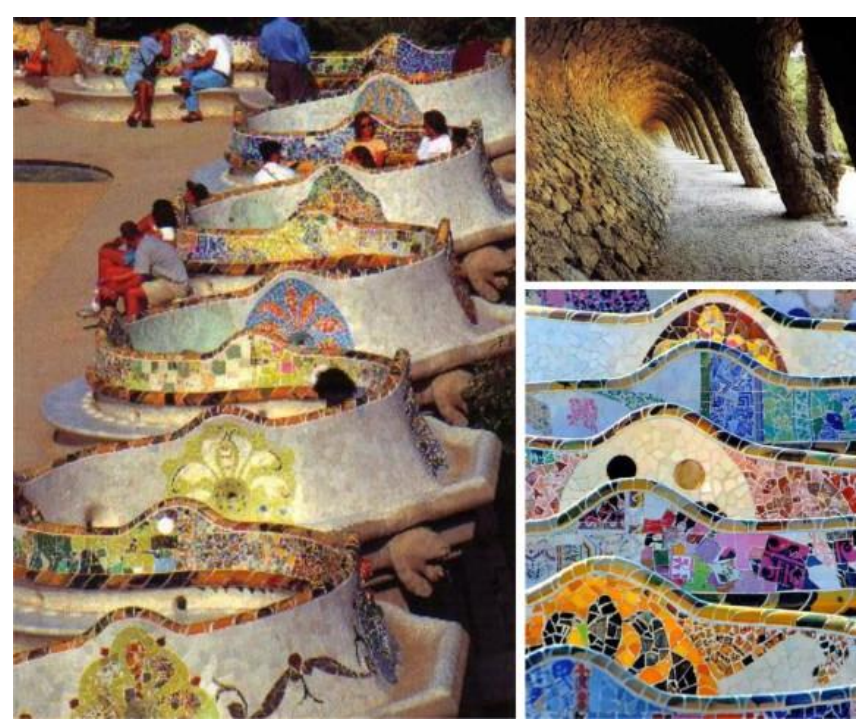

Figure12: Park Guell. Gaudi. Barcelona

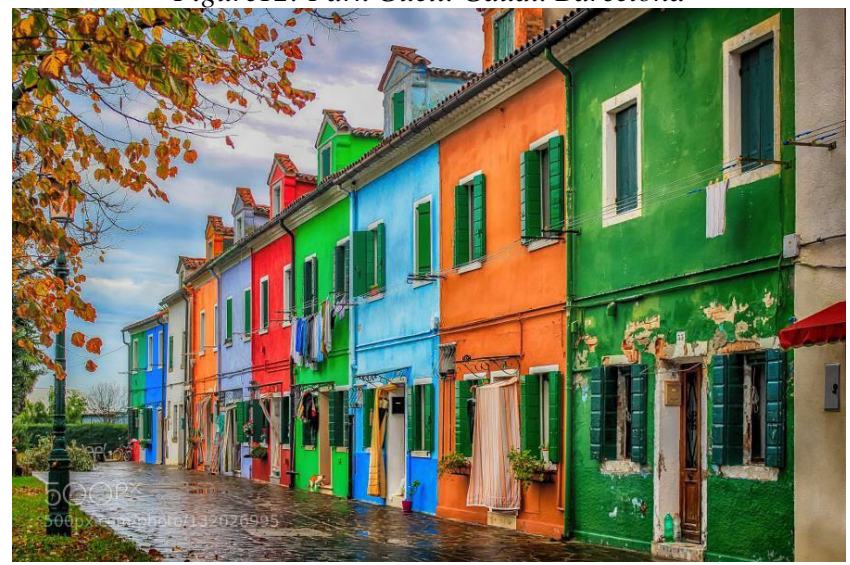

Figure 13: Colorful houses, as a part of a colorful urban fabric.

As a protector of constructions that fit with nature. What's more, it was maybe this that has driven me to wind up one of the great amount of architects who paint their projects with the colors of nature. Most times, when I begin working on a new design, I restrict myself to a palette of browns, whites and grays, particularly in the exteriors. Maybe this was on the grounds that I had not set out to think "out of the box". The normal colors and materials are the safe approach to fit with nature, and since I am a supporter of this hypothesis, it is clear that I would prefer not to be the person who acts against it. 
The two most imperative issues in building designs, are colors and light. In any case, the first, I think it is given less significance than should be expected, in any event from the perspective of architectural design (not from the point of view of interior design).

Being our natural habitat as neutral as it seems to be, the presentation of colored dots is a vital satisfaction in the voyage of life, a breath; it is similar to a rainbow in the sky prompted the area.
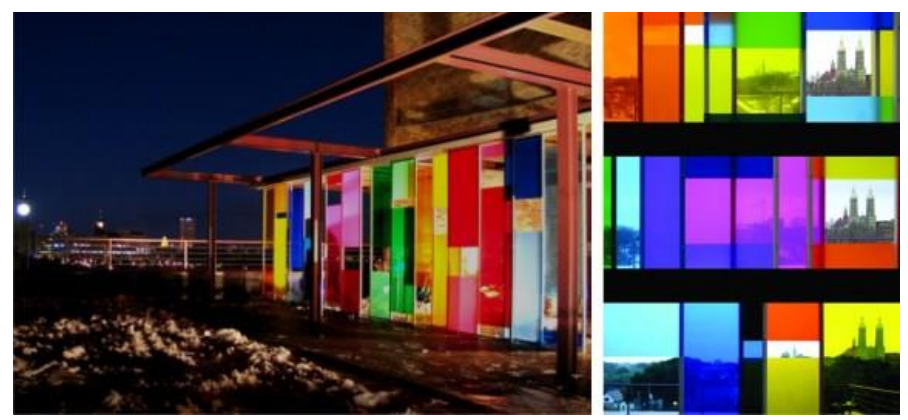

Figure 14: Parts House Pavilion. Johnsen Schmaling Architects. Milwaukee, Wisconsin, USA.

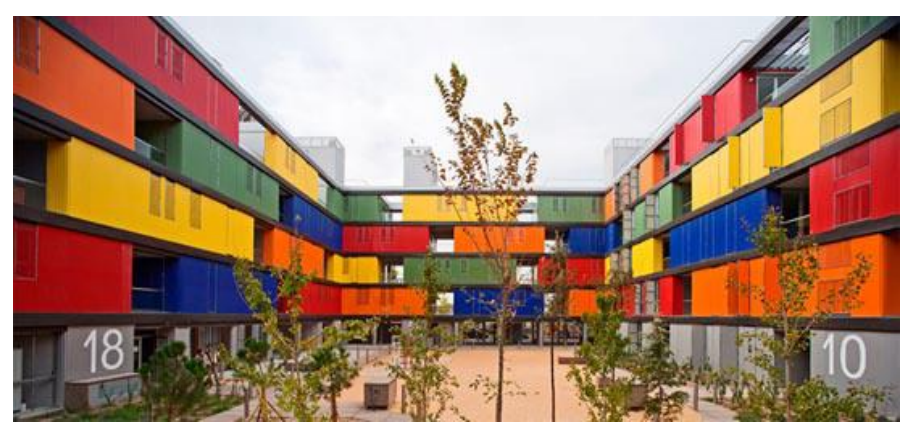

Figure 15: Apartment Building in Madrid. Amann Canovas Maruri Arquitectos.

At the point when connected in urban settings, the color is fit for giving to a particular division, a feeling of having a place with its residents, which may not happen on account of territories with more neutral colors. It has been found, by groups like "let's color project", which advance "an overall activity to change dark spaces with colorful bright paint. A mission to spread colors everywhere throughout the world", that when applying colors in burdened neighborhoods, there have been seen enhancements in the public eye, for example, the lessening of doing crimes rates and the increment of solidarity among its occupants, because they are encouraged to take better care and defend or guard their surroundings, since space is no more unknown.
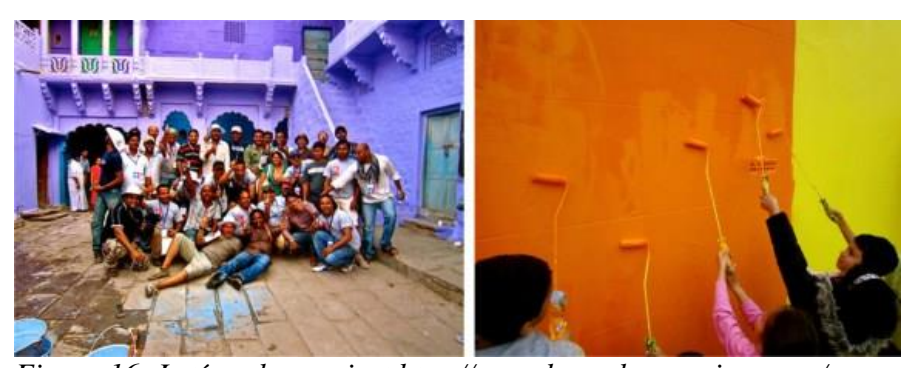

Figure 16: Let's color project http://www.letscolourproject.com/

Innovation and Modernism, particularly in its starting, with its awesome slope towards the utilization of regular materials, made us move far from the delight that create the colors in architectural designs. This has been changing after some time; however, I feel that the changes are not going in the right course. As it happens with most developing aesthetic patterns, whatever was being done, needs to change, if conceivable, completely. We are moving from a grey, brown, natural architectural designs, to ones with such lively colors that stun. We ought not be hesitant to utilize positive colors, which changes the visual progress of the city, yet we must know about how to utilize them; the spots and the extents in which we utilize them, in light of the fact that colors can do a considerable measure for a building and its surroundings, it can likewise hurt them enormously, if not utilized with the important urban awareness.

A sample of this is the Thonik Studio building in Amsterdam, designed by MVRDV, which needed to change its existing facades colors, on account of protestations from local people, who asserted they encountered genuine uneasiness in view of this color.

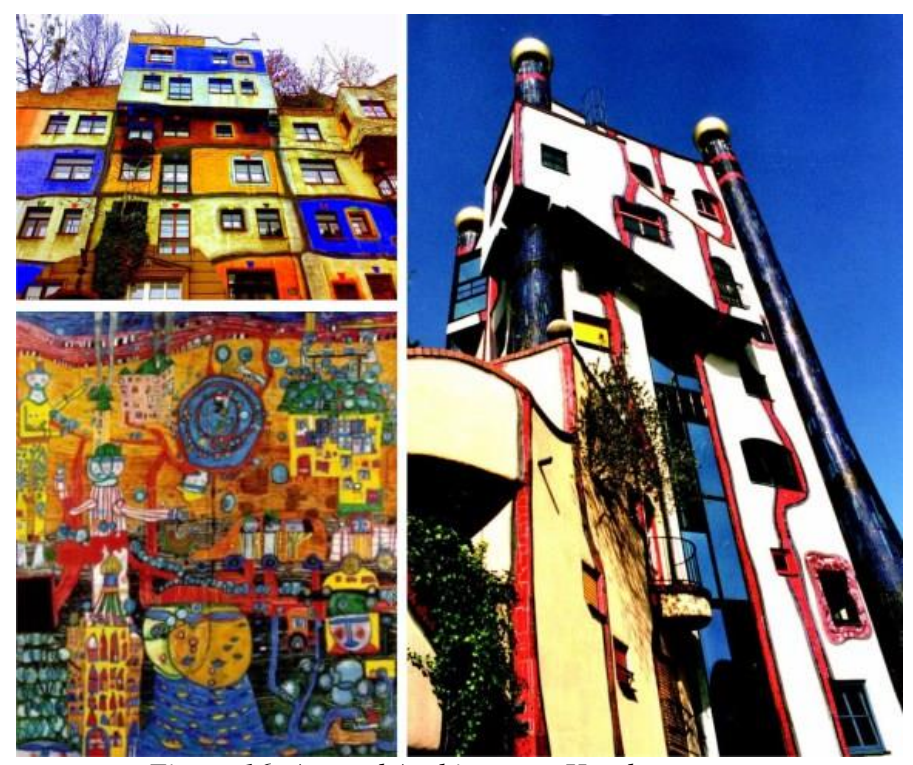

Figure 16: Art and Architecture. Hundertwasser. 


\section{Colors in Nubia- Egypt}

The artistic expressions in old Nubia are categorized into three classes: decorative, symbolic, and utilitarian. The utilitarian expressions incorporated the making of plates, carpets, fans, and jolts from material accessible in the earth, for example, straw and dirt. Ladies honed this work of art. Splendid colors recognized the Nubian structure. The decorative expressions included predominantly dab neckbands and wrist trinkets. Ladies generally made the accessories, and today a business form of these pieces of jewelry is sold in the market. The symbolic expressions included walls and entrances beautification. Decorations were normal of Nubian houses. Symbols of creatures were made to shield houses from the hostile stare. After resettlement, alleviation improvements were supplanted by painting. Most artistic creations have religious themes, and a percentage of the enhancements demonstrate that somebody in the house was blessed to do a pilgrimage to Mecca.

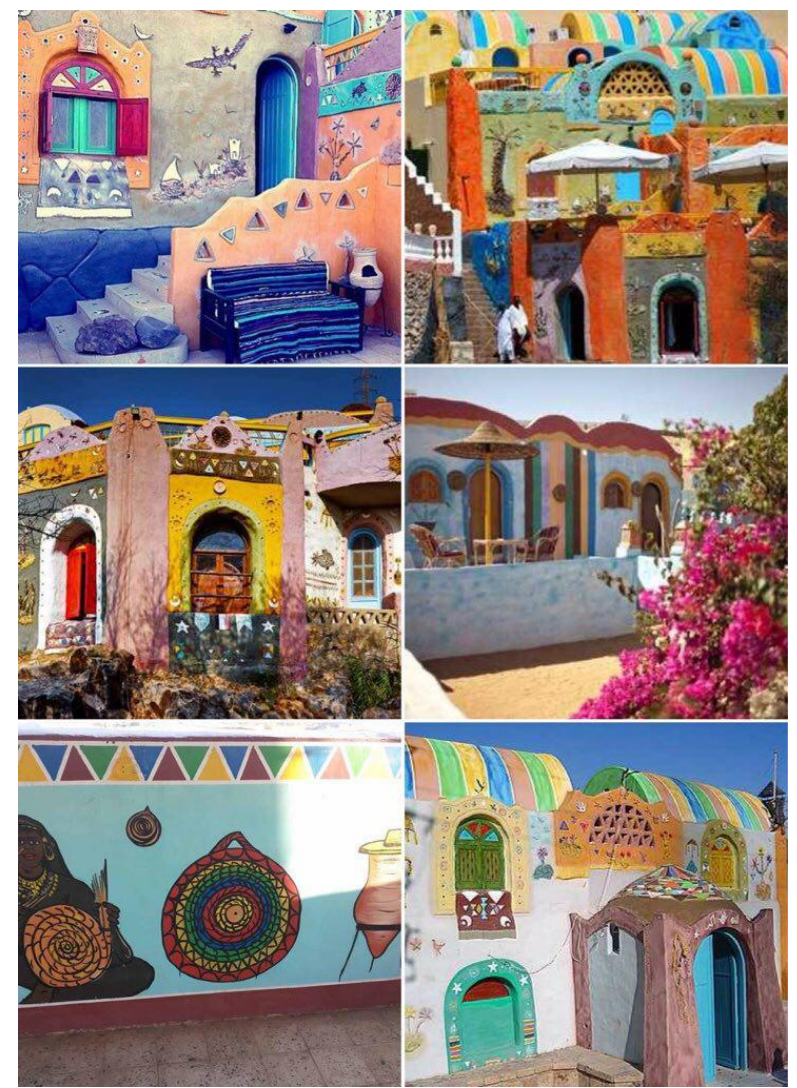

Figure 18: Colorful Nubian village, a vernacular experience of Nubians.

\section{Colors in Islamic Architecture}

Colored Mosaics

Islam prohibits the portrayal of the prophet Mohammad in any illustration, sculpture or other form, and thus a non-figurative style evolved in the hands of Islamic artists who used colored mosaics and patterns to their advantage. Expansive tiled murals decorate the interior walls and spaces of many Islamic mosques in both antiquity and the modern era. The color blue is especially prevalent in these designs, with a variety of shades, including turquoise and deep ultramarine, used to illustrate floral patterns (Echolls, 2015).

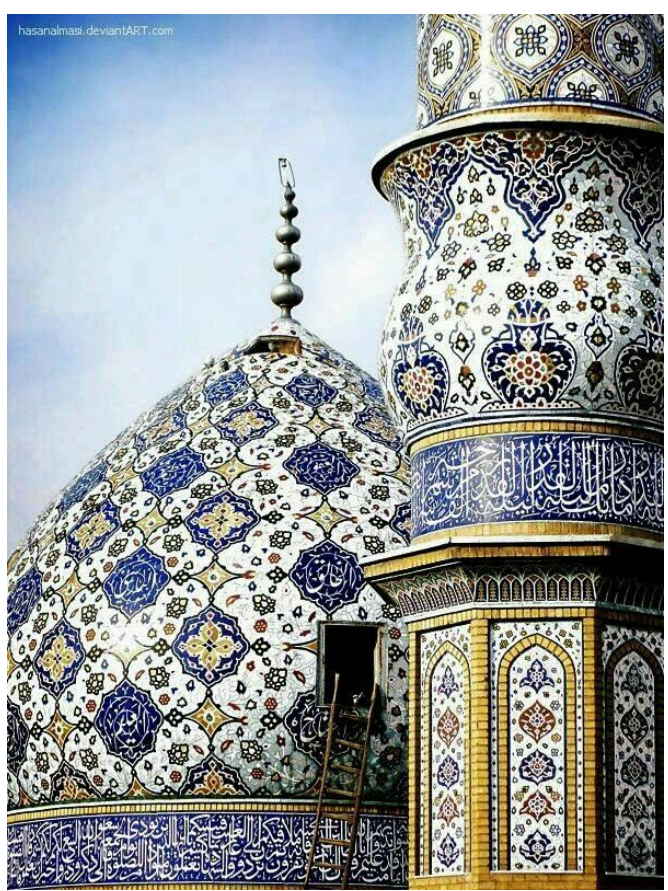

Figure 17: Using colored mosaic tiles in Islamic architecture, with a blue dominant color.

The Red Palace

the Alhambra is a grand and sprawling palace with gardens and courtyards for royalty that stands as a splendid example for use of color in Islamic Architecture in the Spanish city of Granada. Built in the 14th century, Its name means "red palace" for the red-ocher color of its exterior stone walls. While inside the walls and ceilings are decorated with multicolored mosaics, the Alhambra's rich exterior color contrasting with a mountainous background is what makes this structure a recognizable Islamic colorful architectural masterpiece.

\section{The Taj Mahal}

The Taj Mahal is another example of the bold use of natural color in a building's facade to communicate power, piety and riches. Built in India in the 17 th century as a memorial to Shah Jihan's favorite wife, the Taj Mahal is one of the first Indian structures to forgo the standard red sandstone exterior for that of brilliant white marble. The stark white facade has an even greater impact as it's reflected in a massive pool on the grounds of the Taj.

\section{Color in Mosques}

As per Encyclopedia Britannica Online: "color dazzles on the outside of Islamic palaces and memorials, the exterior of some mosques are sometimes muted out of religious modesty. In Turkey, for example, colors are subdued throughout Islamic houses of worship "where a sense of space rather than of overwhelming decoration is preeminent". But in many other Islamic countries like Iran, the splendidly colorful mosaics run free along mosque walls and ceilings in celebration of God. 


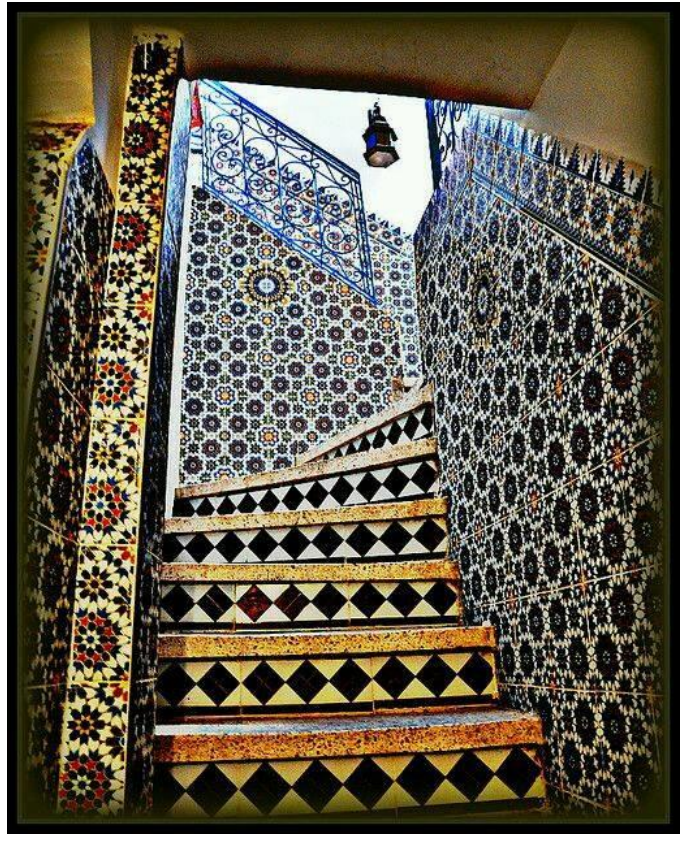

Figure 20: colored verses from Qur'an covering domes and minarets in Islamic Architecture.

\section{E. Colors in Modern Egypt}

In the recent years, Egyptians have seen the rise of numerous "artistic creation" activities, for example, Mashrou al Saada, Color Zone in Suez, Hanlwenha, Cairo Dish Painting Initiative and Coloring a Gray City.

The vast majority of these activities were driven by students fascinated to embellish Egyptian urban communities by coloring and adding pictures to open spaces, for example, walls, staircases, infrastructure, or fences. Other painting activities have developed since 2011: The Cairo Dish Painting Initiative, for example, is a project which concentrates on painting private objects, for example, satellite dishes and sees painting as a chance for self-expression. Another activity, Paint Cairo, is not just inspired by facades painting of casual settlements arranged at the edges of Greater Cairo, additionally in putting them to challenge the shame connected with their unfinished look. two activities are shown here how they tried to have any kind of effect in how inhabitants outwardly encounter their city in particular Mashrou Elsaada and Coloring a Gray City initiatives.

\section{E.1 Mashrou Elsaada \& color therapy}

Mashrou Elsaada was established in 2013, and what motivated starting it was the colossal mental shortfall in a few civilizations that have been expanding in the previous years. This has been clear in the vast majority of Egypt's ghettos, which have been ignored and exhausted by time, much the same as the general population living there. Those individuals hold solid collective values and frame a solid association with the spots they live in. That is the reason why Mashrou Elsaada was planning to bolster those individuals mentally through using shade treatment by utilizing cheerful hues, creative outlines and rousing quotes to change these ghettos and take them back to their previous magnificence. We likewise go for taking a dynamic part in those individuals' lives and help them to add to their own particular future.

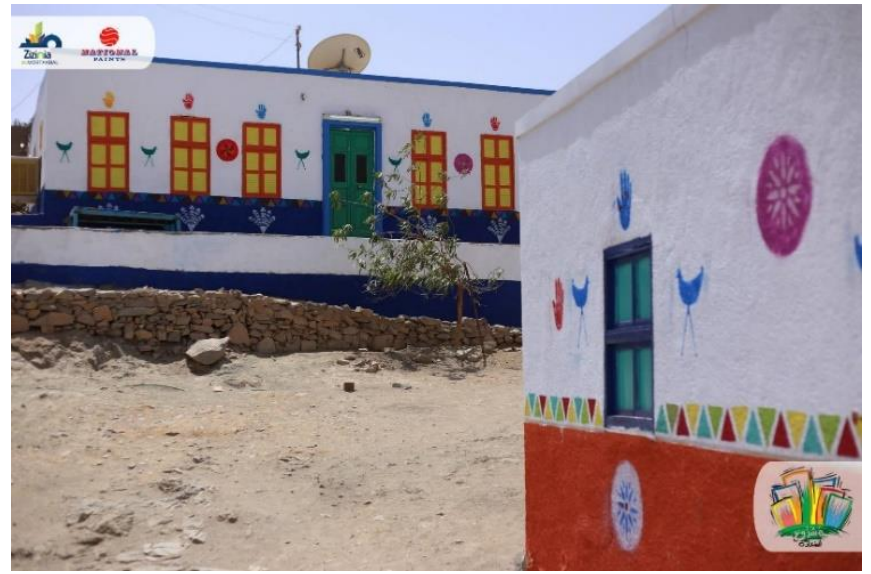

Figure 21: Mashrou Elsaada initiative

\section{E. 2 Coloring a Grey City}

students who will be graduated in 2017 from Faculty of Fine Arts-Zamalek, department of décor, believed that "If you want to see the change, be the change", so since their profession in life is about colors, they chose that their city needs some illumination in its roads. That is the reason they invented the thought of circumventing the city and coloring diverse parts of it to add euphoria and joy to the hearts of individuals. Their dream is to see the entire nation in colors and to add a touch of color to their city and see the adjustment in individuals' lives.
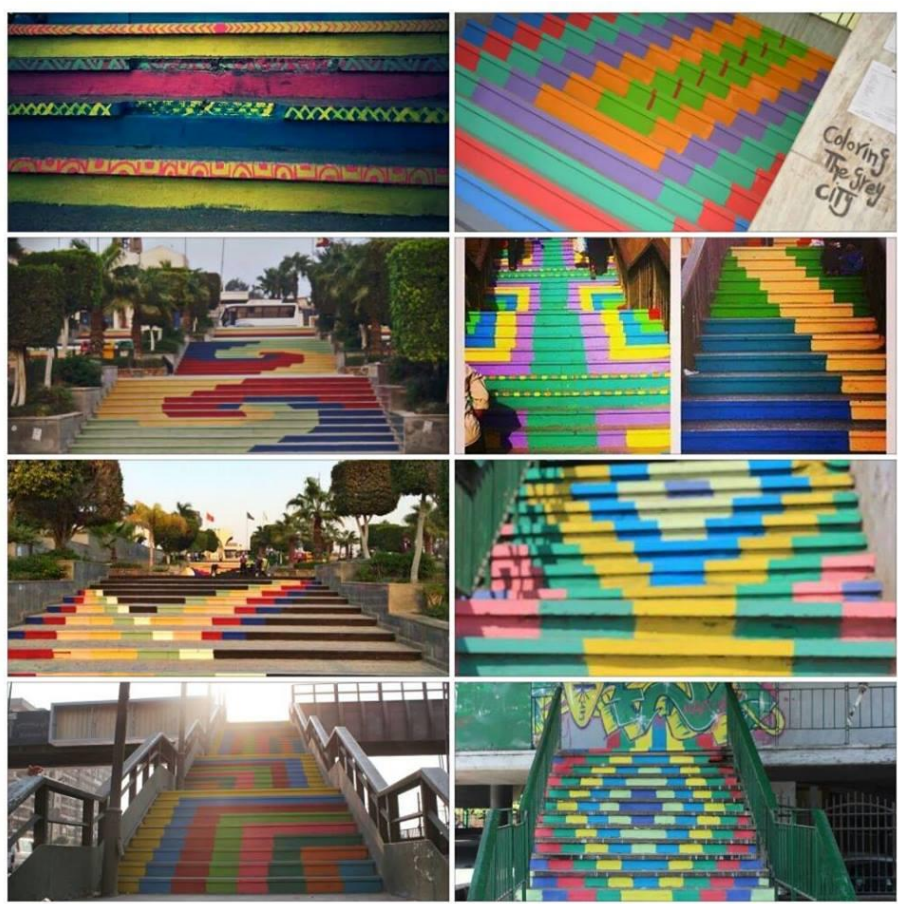

Figure 22: Coloring a grey city initiative, changing grey Cairo into color

\section{FURTHER RESEARCH THAT CAN BE DONE}

More research could be done on how using color on the urban context and slums areas has changed how people act and their first reaction on seeing and accepting the change that has happened to them and their surroundings because of the use of colors. 


\section{CONCLUSIONS}

To sum up, color has approved to be important to the level of being a need for humans, not only to achieve some decorative or aesthetical values, but also to fulfill some needs of the human being that they cannot live without in architectural and urban contexts. It has been mentioned in the Holy Quran in many verses, especially those describing Heaven. In addition to this, color in psychology has a great effect on humans, as different colors can totally change someone's mood as the brain responds differently to different colors. It also has a great effect on humans' emotions, ergonomics, and most apperant in the human aura or energy that it could be used in healing. Moreover, color appears to be so important in humans' life and is related and important to many vital activities of the human being, not only as a fashion or an architects Design for a specific building or an urban planner setup.

\section{ACKNOWLEDGMENT}

The author would like to acknowledge all people who assisted and contributed him in this paper, whether in data gathering, or coordination or any sort of assistance and support.

\section{TABLE OF FIGURES}

Figure 1: Nature is mainly characterized by Colors. 2 Figure 2: Color Wheel 5

Figure 5: Nature containing diversified colors. 6

Figure 3: Colorful Lizard, Example of Colors in Animals. 6

Figure 4: Colorful Flower-Example of colors in plants 6

Figure 6: Colorful Butterfly, examples of Colors in insects 6

Figure 10: The use of natural colors on columns of ancient Egyptian temples, prolonged for centuries. 6

Figure 7: Colors in the ocean 6

Figure 9: The use of colors in temples, imitations of nature. 6

Figure 8: The use of colors inside ancient Egyptian tombs describing their lives in details. 6

Figure 11: Color Meaning Chart 7

Figure12: Park Guell. Gaudi. Barcelona 7

Figure 13: Colorful houses, as a part of a colorful urban fabric. 7

Figure 14: Parts House Pavilion. Johnsen Schmaling Architects. Milwaukee, Wisconsin, USA. 8
Figure 15: Apartment Building in Madrid. Amann Canovas Maruri Arquitectos. 8

Figure 16: Let's color project http://www.letscolourproject.com/ 8

Figure 17: Art and Architecture. Hundertwasser. 8

Figure 19: Using colored mosaic tiles in Islamic architecture, with a blue dominant color. 9

Figure 18: Colorful Nubian village, a vernacular experience of Nubians. 9

Figure 20: colored verses from Qur'an covering domes and minarets in Islamic Architecture. 9

Figure 22: Coloring a grey city initiative, changing grey Cairo into color. 9

Figure 21: Mashrou Elsaada initiative 9

\section{REFERENCES}

[1] Aesthetics., A. a. (2015, Dec). Retrieved from Architeacher: http://www.architeacher.org/

[2] Al-Shawi, M. A. (2014). Significance of Colors in the Noble Quran and the Ethics of Translating Them into English: An Empirical Study on Some Verses. Arab World English Journal, 65-76.

[3] Diab, D. A. (2015). www.quran-m.com. Retrieved from www.quranm.com: http://www.quran-m.com/

[4] Echolls, T. (2015). Colors Used in Islamic Architecture. Retrieved from http://people.opposingviews.com/colors-used-islamic-architecture4676.html

[5] Gerhard Meerwein,Bettina Rodeck Klampenborg, Frank H. Mahnke . (2007). Color - Communication in Architectural Space. Berlin: Birkhäuser; 4., überarb. Aufl.

[6] Jalil, N. A. (2011). Environmental Colour Impact upon Human Behaviour: A. Asia Pacific International Conference on EnvironmentBehaviour Studies (pp. 54-62). North Cyprus: Procedia - Social and Behavioral Sciences.

[7] Mahnke, F. H. (2015). Color in Architecture - More Than Just Decoration. Retrieved from archnet: http://archinect.com/features/article/53292622/color-in-architecturemore-than-just-decoration 